\title{
Thermal generation and (inter)conversion of (multi) cyclopenta-fused polycyclic aromatic hydrocarbons
}

\author{
Leonardus W. Jenneskens, ${ }^{*}$ Martin Sarobe and Jan W. Zwikker. \\ Debye Institute, Department of Physical Organic Chemistry, Utrecht University, \\ Padualaan 8, $3584 \mathrm{CH}$ Utrecht, The Netherlands.
}

\begin{abstract}
FVT of 1,1-dichloro- and/or 1-chloroethenyl substituted PAH's gives access to the CP-PAH's pyracylene (1), cyclopenta[cd]pyrene (12) and benz[ghi]fluoranthene (13), cyclopent [hi] aceanthrylene (18) and cyclopent [hi] acephenanthrylene (19), and the novel cyclopenta[ $c d]$ fluoranthene $(\mathbf{2 2})$ and isomeric cyclopent $[f g]-(\mathbf{2 5 a})$, cyclopent $[j k]-$ (25b) and cyclopent [ $m n]$ acepyrylene (25c), respectively. The propensity of CP-PAH's to interconvert under high temperature FVT conditions is illustrated. Possible mechanisms, such as ring-contraction/ring-expansion via 1,2-H and 1,2-C shifts, are discussed.
\end{abstract}

\section{INTRODUCTION}

The discovery of the new allotropic form of carbon, i.e. the fullerenes, and their accessibility in quantities allowing the exploration of their properties has generated a considerable interest at the interfaces of chemistry, physics and material science (1). Although their properties are more and more unraveled, their preparation by either resistive and arc heating of graphite or in flames, followed by soot extraction, borders on a black box procedure. Hitherto, both carbon monocycles and (cyclopenta-fused) polycyclic aromatic hydrocarbons (CP)-PAH's have been proposed as intermediates in the formation of fullerenes primarily on the basis of mass spectrometry experiments (2). This is reminiscent of our lack in understanding of the chemistry responsible for the formation of (CP)-PAH's during incomplete combustion/pyrolysis of hydrocarbon containing (fossil) fuels (3). This is an unfortunate situation since numerous (CP)-PAH's have been recognized as toxic, mutagenic and/or carcinogenic substances (4). Hence, the elucidation of their build up mechanism, the identification of intermediates involved and the assessment of their thermal properties concomitant with $\mathrm{C}_{\mathrm{n}} \mathrm{H}_{\mathrm{m}}$ composition and topology is of interest to deepen our insight in the factors controlling (CP)-PAH-, fullerene- and soot formation in general.

In this paper we show that (multi-CP)-PAH's, which either have been identified or proposed as combustion effluents or represent fullerene key-substructures, can be conveniently prepared from appropriate PAH precursors using Flash Vacuum Thermolysis [FVT, (5)]. By studying changes in pyrolysate product composition concomitant with temperature, insight in the propensity of these (CP)-PAH's to interconvert under high temperature conditions is obtained.

\section{RESULTS AND DISCUSSION}

Our approach to (multi-CP)-PAH's is inspired by the pioneering work of R.F.C. Brown who demonstrated that under high temperature FVT conditions terminal ethynes isomerize reversibly into ethylidene carbenes. In specific cases the transient carbene is efficiently trapped via an intramolecular $\mathrm{C}-\mathrm{H}$ insertion giving cyclopenta-fused products (6). We envisaged that ethynyl substituted PAH's will be excellent FVT precursors for (multi-CP)-PAH's. However, since ethyne derivatives are susceptible to oligo- $c q$. polymerization at elevated temperatures, 1,1-dichloro- and/or 1-chloroethenyl groups, which are readily accessible by treatment of acetyl substituted PAH's with $\mathrm{PCl}_{5}$, were used instead. Upon FVT (unpacked quartz tube $40 \mathrm{~cm}, \mathrm{p}=0.01$ Torr) they are transformed in situ into the ethynyl substituted PAH's (Fig. 1).

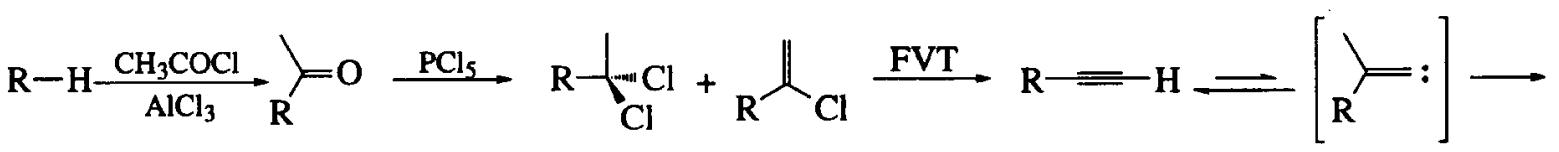

Fig. 1. Preparation of 1,1-dichloro- and 1-chloroethenyl PAH's (R=PAH). 


\section{Pyracylene (1, $\left.\mathrm{C}_{14} \mathrm{H8}\right)$}

Despite the fact that pyracylene (1, cyclopent $[f g]$ acenaphthylene) with its $12-\pi$ electron perimeter is a stable, but reactive, hydrocarbon (7), its chemistry is still unexplored due to difficulties encountered in its synthesis. Although the best preparations of 1 involve FVT (8), in general laborious purification procedures are required for the isolation of analytically pure 1 .

A theoretical investigation of the $\mathrm{C}_{14} \mathrm{H}_{8}$ potential energy surface using the semiempirical AM1 method (9) indicated that 5-ethynylacenaphthene (4) might give an improved access to 1 . To substantiate this prediction 5 being a FVT precursor of 4 was prepared from acenaphthene (6) in two steps (acetylation followed by chlorination (10)) in $62 \%$ overall yield and subjected to FVT. Analysis of the pyrolysates revealed that in the temperature range $700-900^{\circ} \mathrm{C} 5$ is efficiently converted into 4 and subsequently into both $1,2-$ dihydropyracylene (2) and 5-ethynylacenaphthylene (3, Fig. 2). Since the conversion data revealed that

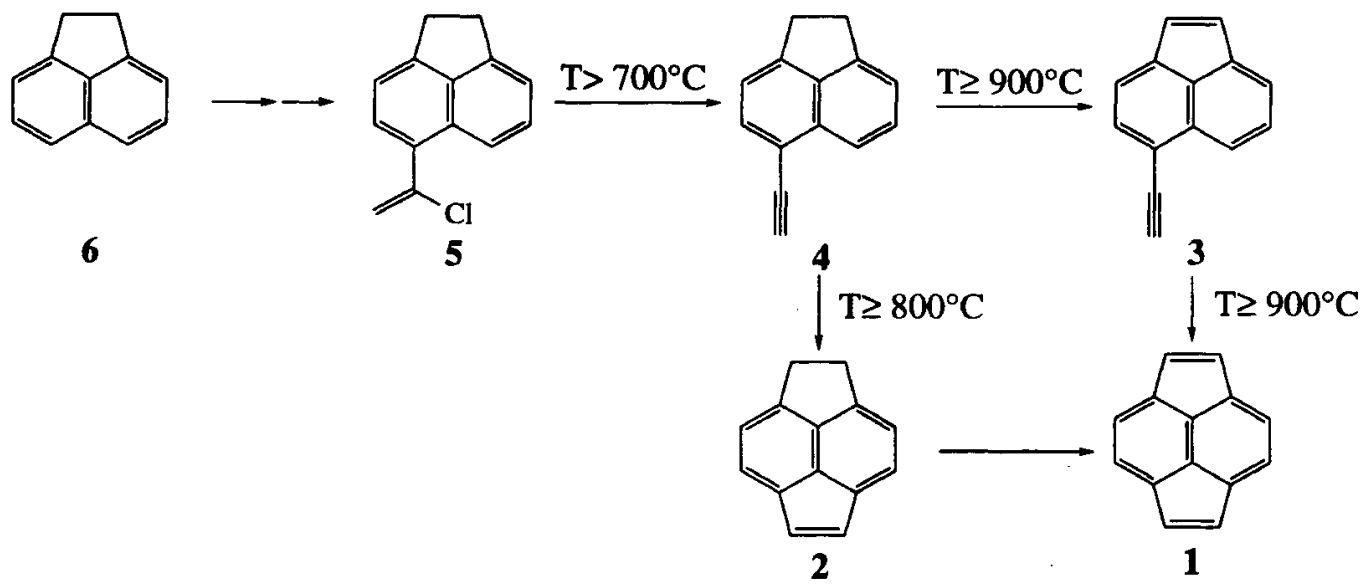

Fig. 2. FVT of 5-(1-chloroethenyl)acenaphthene (5).

2 is already present in the $800-900^{\circ} \mathrm{C}$ pyrolysates, it can be concluded that the second cyclopenta-fusion of 4 to 2 occurs more readily than that of 3 to 1 . This is in line with the results of our calculations (11). Analytically pure 1 was obtained by recrystallization from $n$-pentane at $-20^{\circ} \mathrm{C}$ of the crude $1100^{\circ} \mathrm{C}$ pyrolysate; routine preparations of $0.2 \mathrm{~g}$. quantities in a single FVT run are feasible! It is noteworthy that, although 1 is the major product at $\mathrm{T} \geq 1000^{\circ} \mathrm{C}$, additional fragmentation reactions become competitive. Interestingly, besides the novel products 5-ethenylacenaphthylene and acenaphthylene, small amounts of 1ethynyl- (7) and 3-ethynylacenaphthylene (8) are present (Fig. 3). The identification of 7 and 8 is of interest with respect to the Stone-Wales (S-W) pyracylene rearrangement, i.e. the mutual exchange of two five- and six-membered rings, proposed to rationalize fullerene isomerization (12). Although in the case of 1 this rearrangement cannot be identified without the use of selective ${ }^{13} \mathrm{C}$-labeling, the formation of 7 and 8 can also be interpreted as evidence for the occurrence of a ring-contraction/ring-expansion (RC/RE) via a (consecutive) 1,2-H and 1,2-C shift giving cyclopenta[bc]acenaphthylene (9, Fig. 3). The intermediacy of 9 has been invoked to rationalize the conversion of 7 to 8 and vice versa under high temperature FVT conditions (13)! However, the formation of 7 and 8 can also be rationalized directly with a ringcontraction/ring-expansion of 5-ethynylacenaphthylene (3 (14)). Clearly, $13 \mathrm{C}$-labeling studies are required to shed light on these phenomena; experiments are in progress and the results will be reported elsewhere (11).

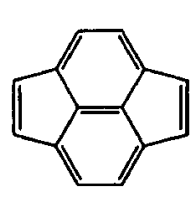

1
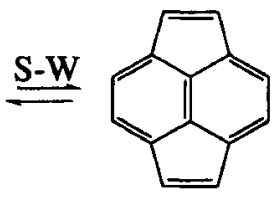

1
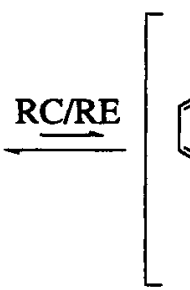

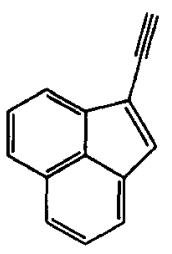

7

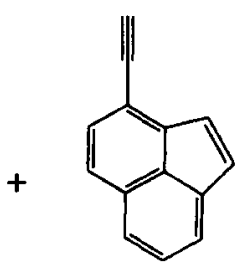

8

Fig. 3. Stone-Wales (S-W) pyracylene rearrangement $v s$ ring-contraction/ring-expansion (RC/RE)? 


\section{Cyclopenta[cd]pyrene (12) and benz[ghi]fluoranthene (13, C18H10).}

FVT of 1-(1-chloroethenyl)pyrene (10) at $1000^{\circ} \mathrm{C}$ gives the abundant combustion effluent cyclopenta[cd]pyrene (12) in nearly quantitative yield with a mass recovery of $90 \%(10)$. The unequivocal identification of 1 -ethynylpyrene $(11)$ as the primary product at $\mathrm{T} \leq 800^{\circ} \mathrm{C}$ provided compelling evidence that 12 is formed via an ethynyl-ethylidene carbene rearrangement followed by an intramolecular carbene insertion. Interestingly, analysis of the $\mathrm{T} \geq 1000^{\circ} \mathrm{C}$ pyrolysates revealed that, besides 12 , benzo[ghi]fluoranthene $(13)$ is present in minute amounts. The conversion of 12 into 13 can be rationalized by invoking a ring-contraction/ring-expansion mechanism in which via a 1,2-H and 1,2 $\mathrm{C}$ shift a fivemembered ring is converted into a six-membered ring and vice versa under the high temperature FVT conditions [vide supra, (14)]. Indeed, independent FVT of 12 at $\mathrm{T} \geq 1000^{\circ} \mathrm{C}$ gave pyrolysates containing both 12 and $13\left(1050{ }^{\circ} \mathrm{C}, 12 / 1399 / 1 \%\right.$ and $1150{ }^{\circ} \mathrm{C}, 12 / 1397 / 3 \%$, Fig. 4). Note that it has been established that 13 also rearranges to 12 under similar FVT conditions [1175 ${ }^{\circ} \mathrm{C}, 12 / 13$ 12/35\% (15)].<smiles>C=C(Cl)c1ccc2ccc3cccc4ccc1c2c34</smiles>

10

\section{$\mathrm{T} \geq 700^{\circ} \mathrm{C}$}<smiles>C#Cc1ccc2ccc3cccc4ccc1c2c34</smiles>

11

$\mathrm{T} 1000^{\circ} \mathrm{C}$

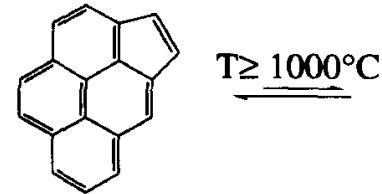

12<smiles></smiles>

13

Fig. 4. FVT of 1-(1-chloroethenyl)pyrene (10).

\section{Interconversion of cyclopent $[h i]$ aceanthrylene (18) into cyclopent $[h i]$ acephenanthrylene} $\left(19, C_{18 H 10}\right.$.

FVT of 1,5 -bis(1-chloroethenyl)anthracene (14) in the temperature range $600{ }^{\circ} \mathrm{C}-1100^{\circ} \mathrm{C}$ gave cyclopent [hi] aceanthrylene (18) in two consecutive cyclopenta-fusion steps. Note that the intermediate 7-ethynylaceanthrylene (16) does not rearrange to 7-ethynylacephenanthrylene (17), but is completely converted to 18 at $\mathrm{T} \geq 800^{\circ} \mathrm{C}$. This strongly indicates that the second cyclopenta-fusion process is more viable than the rearrangement. In the temperature range $900-1100^{\circ} \mathrm{C}$, the conversion data and independent repyrolysis experiments unambiguously showed that 18 is ultimately converted into 19. Apparently, this conversion involves again a ring-contraction/ring-expansion process (vide supra). Although 19 may rearrange even further to 13 no evidence for its formation was found (Fig. 5). A comparison of the extent of conversion of 18 into 19 with that of the monocyclopenta-fused analogue aceanthrylene into acephenanthrylene (14) revealed that 18 rearranges more rapidly under similar FVT conditions. These observations provide a rationalization for the prevalent presence of 19 , instead of 18 (4), as one of the abundant combustion effluents (16).

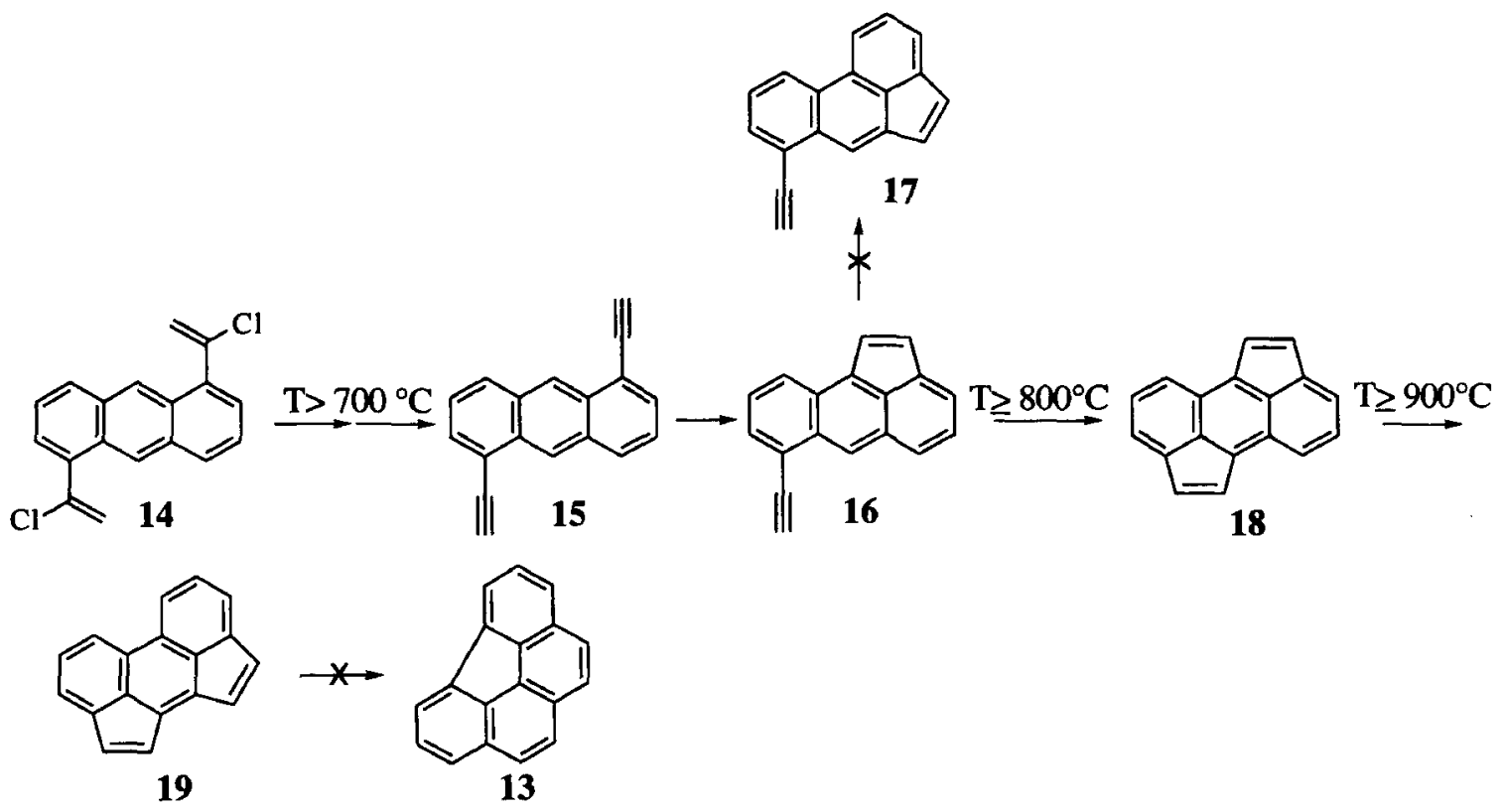

Fig. 5. FVT of 1,5-bis(1-chloroethenyl)anthracene (14). 
Cyclopenta[cd]fluoranthene: acefluoranthylene $(22, \mathrm{C} 18 \mathrm{H10})$.

In the $\mathrm{C}_{18} \mathrm{H}_{10}$ series preparations of cyclopenta[cd]fluoranthene $(22$, acefluoranthylene) and cyclopent $[f g]$ aceanthrylene $(23$, benz [d]pyracylene) have not been reported yet. Recently, cyclopenta[cd]fluoranthene (22) was obtained by FVT at $1050^{\circ} \mathrm{C}$ of 3-(1-chloroethenyl)fluoranthene (20, mass recovery $88 \%$ ). Precursor 20 was prepared by chlorination of readily accessible 3-acetylfluoranthene. Recrystallization from ethanol at $4{ }^{\circ} \mathrm{C}$ of the crude $1050^{\circ} \mathrm{C}$ pyrolysate gave analytically pure 22 as red needles (m.p. $141.7^{\circ} \mathrm{C}$, Fig. 6). It should be stipulated that despite the excellent mass recovery at $\mathrm{T}>$

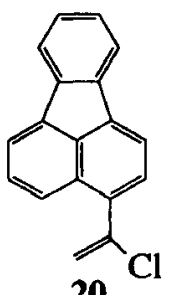

20<smiles>c1ccc2c(c1)c1cccc3c2cccc13</smiles>

21

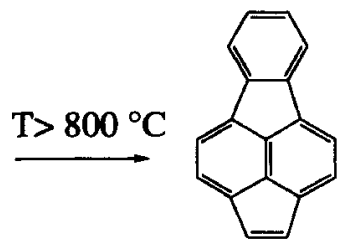

22

Fig. 6. FVT of 5-(1-chloroethenyl)fluoranthene (20).

$1000{ }^{\circ} \mathrm{C}$, some fragmentation of 22 occurs. No evidence for the occurrence of a Stone-Wales (S-W) pyracylene-type rearrangement (12), which in the case of 22 would give the other unknown $\mathrm{C}_{18} \mathrm{H}_{10}$ isomer 23, was obtained (Fig. 7)! Neither 20 nor 22 gave access to 23 upon FVT at T>1000 ${ }^{\circ} \mathrm{C}$. Note that semiempirical AM1 (9) calculations predict that $\mathbf{2 3}$ is considerably less stable than $\mathbf{2 2}$.

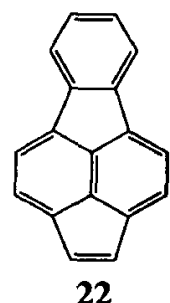

140.9

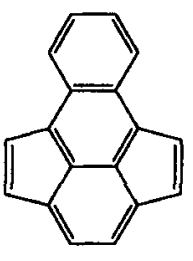

23

158.1

Fig. 7. Stone-Wales (S-W) rearrangement of cyclopenta[cd]fluoranthene (22).

Since 22 is a benz[a]-fused analogue of 1 , which is susceptible to decomposition in dilute solution and upon heating in the solid state, the thermal stability of 22 was investigated. Decomposition was neither discernable after heating in $\mathrm{C}_{6} \mathrm{D}_{6}$ at $65^{\circ} \mathrm{C}$ for $24 \mathrm{~h}$ nor upon heating in the solid state using DSC (temperature range -10 to $160^{\circ} \mathrm{C}$ ) and in an ampoule $\left(160^{\circ} \mathrm{C}\right.$ for $1 \mathrm{~h}, 1_{\mathrm{H}} \mathrm{HMR}$ spectroscopy and HPLC)! Nevertheless in analogy to the acenaphthylene/pyracylene couple (7), cyclopenta-fusion has a profound effect on the electronic properties. Cyclic voltammetry showed that 22 , in contrast to fluoranthene, possesses two reversible halfwave reduction potentials $\left(\mathrm{ERED}_{1 / 2}(0 /-1)-1.33 \mathrm{~V}\right.$ vs $\mathrm{SCE}$ and $\mathrm{E}^{\mathrm{RED}} 1 / 2(-1 /-2)-1.86 \mathrm{~V}$ vs $\left.\mathrm{SCE}\right)$. For fluoranthene only one quasi-reversible halfwave reduction potential at $\mathrm{E}^{\mathrm{RED}} 1 / 2-1.92 \mathrm{~V}$ vs $\mathrm{SCE}$ is found. A $0.59 \mathrm{~V}$ shift of $E^{R E D} 1 / 2(0 /-1)$ in going from fluoranthene to 22 is observed! The effect of cyclopenta-fusion is also reflected by UV/Vis and fluorescence spectroscopy. In UV/Vis all bands of 22 are considerably redshifted (range 10-50 nm). Finally, whereas fluoranthene and dihydrocyclopenta[cd]fluoranthene obtained by catalytic hydrogenation of $\mathbf{2 2}$ strongly fluoresce, 22 itself does not fluoresce at all upon excitation in the different absorption bands (17).

\section{Cyclopent $[f g]$ acepyrylene (25a), cyclopent $[j k]$ acepyrylene (25b) and cyclopent $[m n]$ ace-} pyrylene (25c, $\mathrm{C}_{20} \mathrm{H}_{10}$ ).

The hitherto unknown $\mathrm{C}_{20} \mathrm{H}_{10} \mathrm{CP}-\mathrm{PAH}$ 's, cyclopent[fg]-(25a), cyclopent[jk]-(25b) and cyclopent $[\mathrm{mn}]$ acepyrylene $(25 \mathrm{c})$ have been proposed to be intermediates in carbon network formation at high temperatures (18) and as important combustion effluents (19). FVT at $1100^{\circ} \mathrm{C}$ of the appropriate bis(1chloroethenyl)pyrenes (24a-c) prepared by chlorination of the corresponding bis(acetyl)pyrenes gave pyrolysates from which the cyclopentacepyrylenes 25a-c, respectively, could be isolated by crystallization (Fig. 8). Analysis of the $700-1100^{\circ} \mathrm{C}$ pyrolysates unequivocally showed that bis(cyclopenta-fusion) is a consecutive process.

A survey of the ${ }^{1} \mathrm{H}$ NMR chemical shifts of the cyclopenta-protons revealed the profound influence of bis(cyclopenta-fusion) topology. Although the 3 JHH coupling constants $(5.1-5.4 \mathrm{~Hz})$ indicate that $25 \mathrm{a}-\mathrm{c}$ 


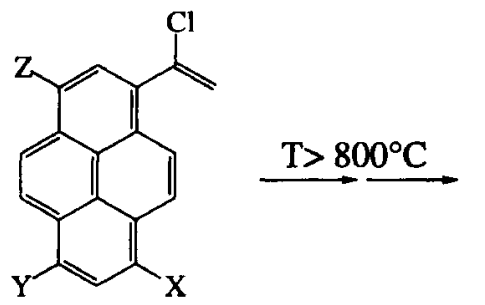

24a: $\mathrm{X}=-\mathrm{CClCH}_{2}, \mathrm{Y=H}, \mathrm{Z}=\mathrm{H}$

b: $X=\mathrm{H}, \mathrm{Y}=-\mathrm{CClCH}_{2}, Z=\mathrm{H}$

c: $X=\mathrm{H}, \mathrm{Y}=\mathrm{H}, \mathrm{Z}=-\mathrm{CClCH}_{2}$<smiles>c1cc2ccc3ccc4ccc5ccc1c1c2c3c4c51</smiles>

25a<smiles></smiles>

25b<smiles>c1cc2cc3ccc4cc5cccc6cc(c1)c(c2)c6c5c34</smiles>

25c

Fig. 8. FVT of the bis(1-chloroethenyl)pyrenes (24a-c).

possess cyclopentene-type alkenic bonds, substantial differences are found between their chemical shifts (25a, $\delta 7.01$ and $6.78,25 \mathrm{~b}, \delta 6.70$ and 6.61 and $25 \mathrm{c}, \delta 7.50$ and $7.22 \mathrm{ppm}$ ). Compared to cyclopenta[cd]pyrene $[12, \delta 7.45$ and $7.23,3 \mathrm{JHH} 5.3 \mathrm{~Hz},(10)]$ these protons become more shielded in the series 25c, 25a to 25b indicative for the presence of paramagnetic ring current contributions. The effect of bis(cyclopenta-fusion) is also reflected by the UV/Vis spectra of 25a-c. The spectra of 25a and 25c resemble those of 19 and 12, respectively. In contrast, 25b possesses a markedly different UV/Vis spectrum; bathochromic shifts of all bands and vibronic couplings are observed. Hydrogenation of 25a-c quantitatively gave the related bisdihydrocyclopentacepyrylenes, respectively, which all possess pyrene-like $\mathrm{UV} / \mathrm{V}$ is spectra. Steady-state fluorescence spectroscopy shows that $\mathbf{2 5 a}$ and $\mathbf{2 5 c}$ fluoresce, while $\mathbf{2 5 b}$ is inactive. In contrast to $\mathbf{1 2}$, the Kasha-Vavilov rule applies for $\mathbf{2 5 a}$ and $\mathbf{2 5 c}$, i.e. their fluorescence is independent on the excitation wavelength.

With regard to the propensity of $\mathbf{2 5 a - c}$ towards carbon network formation the following remarks apply. At $\mathrm{T} \geq 900{ }^{\circ} \mathrm{C}$ a decrease in mass recovery (90\% to $25 \%$ ) is found upon FVT of 24a-c. Concurrently, besides 25a-c, an intractable polymer film is deposited immediately behind the hot zone. The resemblance of the IR spectra of these polymers in combination with the strong band at $2900 \mathrm{~cm}^{-1}[\mathrm{v}(\mathrm{C}-\mathrm{H})$ stretch vibrations] and the absence of $v(C \equiv C)$ at $2100 \mathrm{~cm}^{-1}$ and $v(\equiv C-H)$ at $3310 \mathrm{~cm}^{-1}$ stretch vibrations indicates that the cyclopentene double bonds of 25a-c are susceptible to oligo- $c q$. polymerization (20)!

Thermolysis of benz[c]phenanthrene (26). Conversion of an alternant $\mathrm{C}_{18 H 12}$ PAH into the non-alternant $\mathrm{C}_{18 \mathrm{H}_{10}}$ (CP)-PAH's cyclopenta[cd]pyrene (12) and benz[ghi]fluoranthene (13).

Although it has been reported that benz[c]phenanthrene (26) cannot be converted to benz [ghi]fluoranthene (13) under FVT conditions (15), we have recently shown that at $\mathrm{p}=0.5$ Torr and $\mathrm{T} 1150^{\circ} \mathrm{C}$ (flow thermolysis conditions, $\mathrm{N}_{2}$ carrier gas), 26 is converted to $12(40 \%)$ and $13(30 \%$, mass recovery $60 \%)$. At $p=1$ Torr only carbonization occurs; no low molecular weight products could be identified. Since the temperature conversion data suggest that no clear interrelationship exists between the formation of 12 and 13, we anticipate that at least two competitive processes as shown in Fig. 9 involving either an aryl radical cyclization or a benzyne 27 - cyclopentadienylidene carbene 28 (6) rearrangement are operational (11).

$-2 \mathrm{H}$ (aryl radical cyclization)

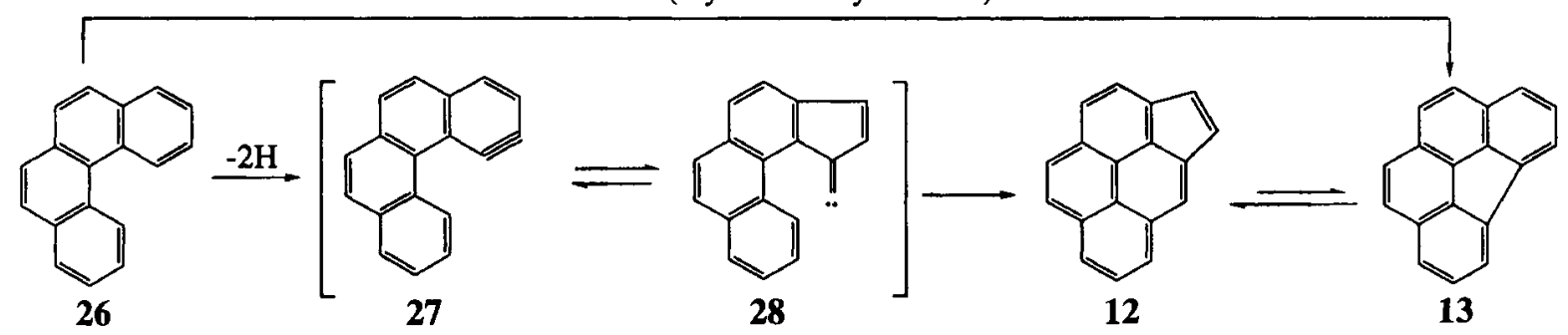

Fig. 9. Thermolysis of benz $[c]$ phenanthrene (26).

Automerization of acenaphthylene (29, $\left.\mathrm{C}_{12} \mathrm{H}_{8}\right)$ : semiempirical AM1 calculations.

To gain insight in the viability of the ring-contraction/ring-expansion via a consecutive $1,2-\mathrm{H}$ and $1,2-\mathrm{C}$ shift as a common mechanism for the interconversion of (CP)-PAH's under high temperature conditions, the generic acenaphthylene (29) has been studied using the semiempirical AM1 method. In the case of ${ }^{13} \mathrm{C}$ labeled 29 compelling evidence has been reported supporting the occurrence of a ring-contraction/ringexpansion process under high temperature conditions (14). Both 29 and 30 were identified as minima and transition states connecting 29 to 30 (1,2-H shift) and 30 to 29 (1,2-C shift) were succesfully located. 


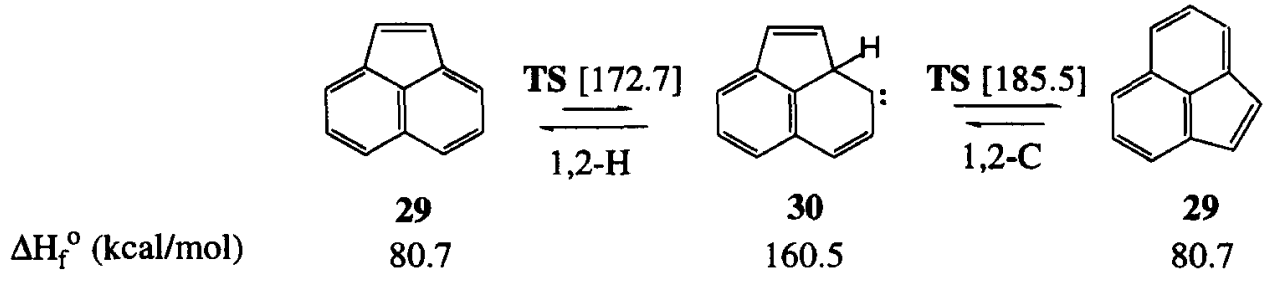

Fig. 10. Automerization of acenaphthylene (29): semiempirical AM1 calculations.

Since AM1 overestimates the activation energy for 1,2-H shifts (9), our results indicate that the 1,2-C shift constitutes the rate determining step (Fig. 10). This is in line with ab initio data for the interconversion of benzene into fulvene and vice versa by a similar mechanism (21). Currently, the potential energy surfaces of the (CP)-PAH's described in this paper are under investigation and results will be reported elsewhere (11).

\section{CONCLUSIONS}

FVT of (multi) 1,1-dichloro- and/or 1-chloroethenyl substituted PAH's provides access to (multi-CP)PAH's which either have been been identified or proposed as abundant combustion effluents or represent fullerene key-substructures. In addition, the conversion data derived from pyrolysate product compositions gives valuable insight in the thermal behaviour of (CP)-PAH's under high temperature conditions especially with respect to their propensity to interconvert selectively.

Acknowledgements: Financial support (M.S.) from the Gobierno Vasco and contributions by our coworkers whose names appear in the references are gratefully acknowledged.

\section{REFERENCES}

1. H.W. Kroto, A.W. Allaf and S.P. Balm Chem. Rev. 91, 1213 (1991) and references cited.

2. T.-M. Chang, A. Naim, S.N. Ahmed, G. Goodloe and P.B. Shevlin J. Am. Chem. Soc. 114, 7603 (1992); T. Belz, H. Werner, F. Zemlin, U. Klengler, M. Wesemann, B. Tesche, E. Zeitler, A. Reller and R. Schlögl Angew. Chem. Int. Ed. Engl. 33, 1866 (1994) and references cited.

3. H.W. Kroto J. Chem. Soc., Faraday Trans. 87, 2871 (1991).

4. For example: A.L. Lafleur, J.P. Longwell, J.A. Marr, P.A. Monchamp, E.F. Plummer, W.G. Thilly, P.P.J. Mulder, B.B. Boere, J. Cornelisse and J. Lugtenburg Environmental Health Perspectives 101, 146 (1993).

5. R.F.C. Brown, Pyrolytic Methods in Organic Chemistry, Organic Chemistry Monographs, Academic Press, Vol. 41, New York (1980).

6. For a review: R.F.C. Brown and F.W. Eastwood SYNLETT 9 (1993) and references cited.

7. B. Freiermuth, S. Gerber, A. Riesen, J. Wirz and M. Zehnder J. Am. Chem. Soc. 112, 738 (1990).

8. G.J. Schaden J. Org. Chem. 48, 5385 (1983) and references cited; E.V. Dehmlov and M. Fründ Z. Naturforsch. 47b, 1647 (1992); L.T. Scott and H.B. Warren, 7th Intern. Symp. on Novel Arom. Comp. Victoria, Canada, July 19-24 (1992), abstract 65.

9. M.J.S. Dewar, E.G. Zoebisch, E.F. Healy and J.J.P. Stewart J. Am. Chem. Soc. 107, 3902 (1985).

10. For synthetic procedures: M. Sarobe, J.W. Zwikker, J. D. Snoeijer, U.E. Wiersum and L.W.

Jenneskens J. Chem. Soc., Chem. Commun. 89 (1994).

11. M. Sarobe and L.W. Jenneskens, manuscript in preparation.

12. A.J. Stone and D.J. Wales Chem. Phys. Lett. 128, 501 (1986).

13. R.F.C. Brown, F.W. Eastwood and N.R. Wong Tetrahedron Lett. 34, 1223 (1993).

14. L.T. Scott and N.H. Roelofs J. Am. Chem. Soc. 109, 5461 (1987); L.T. Scott and N.H. Roelofs Tetrahedron Lett. 29, 6857 (1988).

15. M. John Plater Tetrahedron Lett. 35, 6147 (1994).

16. M. Sarobe, J. D. Snoeijer, L.W. Jenneskens, J.W. Zwikker and J. Wesseling Tetrahedron Lett. in press (1995).

17. M. Sarobe, J. D. Snoeijer, L.W. Jenneskens, M. Q. Slagt and J.W. Zwikker Tetrahedron Lett. in press (1995); see also reference 22.

18. S.E. Stein Acc. Chem. Res. 24, 350 (1991) and references cited.

19. A.L. Lafleur, J.B. Howard, J.A. Marr and T. Yadav J. Phys. Chem. 96, 13539 (1993).

20. M. Sarobe, S. Flink, L.W. Jenneskens, B.L.A. van Poecke and J.W. Zwikker J. Chem. Soc., Chem. Commun. in press (1995); see also reference 22.

21. K.M. Mertz, Jr. and L.T. Scott J. Chem. Soc. Chem. Commun., 412 (1993).

22. Compounds 22 and 25a-c have been prepared independently by L.T. Scott et al. (Boston College); this issue of Pure \& Appl. Chem. and L.T. Scott and A. Necula J. Org. Chem. in press (1995). 